\title{
Lived experiences of male nurses: Dire consequences for the nursing profession
}

\author{
Suzanne Kronsberg, Josephine Rachel Bouret, Anne Liners Brett* \\ University of Phoenix, Phoenix, Arizona, United States
}

Received: July 19, 2017

DOI: $10.5430 /$ jnep.v8n1p46
Accepted: August 16, 2017

URL: https://doi.org/10.5430/jnep.v8n1p46

\begin{abstract}
The current and impending nursing shortage is well documented in the literature. Nursing needs to look at alternative strategies to meet the demands faced by the nursing shortage in both practice and education. One strategy would be to increase the number of men in nursing. While the percentage of men in nursing has increased incrementally, male nurses are underrepresented in nursing constituting approximately $9.6 \%$ of the nursing workforce. Two independent studies resulted in strikingly similar findings suggesting that male nurses are experiencing discrimination, lack of support, and dissatisfaction in the educational and practice environments. To increase the recruitment and retention of men in nursing it is imperative that this critical problem be addressed by nurse educators, managers, and practitioners at every level.
\end{abstract}

Key Words: Male nurse, Discrimination, Stereotyping, Lateral violence, Phenomenology

\section{INTRODUCTION}

Society has long held a set of perceptions that specific professions are relegated to specific genders. These perceptions have started to change in the last few years. In 2017, more women are found in formerly male dominated roles. However, female-dominated professions have not shown the same increase in males, and no field better exemplifies this than the field of nursing. ${ }^{[1]}$

Men have increased from $7 \%$ of the US workforce in nursing in $2006,{ }^{[2]}$ to $9.6 \%$ in $2013 .{ }^{[3]}$ Although there has been an increase in men entering the nursing profession in the last 10 years, it has been a small, slow rise. The United States is expected to experience an increase in the shortage of nurses in the near future as a result of a return to prerecession work levels, health care reform, aging baby boomers, and the insufficient numbers of nursing school graduates. Specifically more nurses will be needed to care for the aging population, the rise in chronic care management needs, and the increasing demand for quality nursing care and services. ${ }^{[4]}$ Therefore, the United States must recruit a surge of new nurses to meet the growing need as well as encourage nurses to continue their education to be prepared as nursing faculty. ${ }^{[5]}$ There is a need to explore opportunities to recruit and retain men in the nursing profession as a viable way to address the impending nursing shortage and to promote gender diversity in nursing to mirror the culture that nurses care for.

Social Role Theory and the history of men in nursing together provides considerable insight into the dynamic faced by male nurses in education and practice. Social Role Theory posits that gender differences in adult social behaviors are determined more by adult social roles than biology. Women are associated with more communal traits of being warm, nurturing, friendly, unselfish, expressive, and emotionally supportive. Men are associated with more agentic traits of being independent, assertive, competitive, and aggressive. The differences in family and occupational roles occupied by

*Correspondence: Anne Liners Brett; Email: annebrett@email.phoenix.edu; Address: University of Phoenix, Phoenix, Arizona, United States. 
men and women forms the basis for stereotypes and gendercorrelated expectations about behaviors. ${ }^{[6]}$ Due to genderrole stereotyping members of society question the capacity of specific genders to occupy a certain position in society. An example is men in nursing. Stereotypes account for many of the difficulties men experience when trying to function in a profession that is traditionally viewed as a "woman's profession". [7]

\section{Literature REVIEW}

\subsection{History}

Evans (2004) suggested that men in nursing predated Florence Nightingale. Military orders of male nurses included the Order of St. John of Jerusalem which was founded in the eleventh and twelve centuries. In addition to protecting pilgrims, they built hospitals throughout Europe to lodge and care for the sick. Monastic orders of male nurses were represented by groups such as the Brothers of St. Anthony, established in 1605 to care for erysipelas victims. Florence Nightingale feminized nursing and diminished men's role in the profession. Florence Nightingale, modern day nursing's founder, established nursing as a women's profession in the middle of the nineteenth century. This brought the participation of men in nursing to an abrupt end. Male nursing from the 19th century to the present shows that men were able to participate in nursing but many times were restricted in their activities. The Nurses Act of 1919 in England required male nurses to be on a separate register thereby segregating men and women within the profession. Segregation of labor was demonstrated with male nurses assigned to roles in asylums where their physical strength was sought to subdue violent patients. ${ }^{[8]}$

Threat (2010) ${ }^{[9]}$ posited that social and political influences have restricted men from working and participating fully in nursing. The author focused on the exclusion of non-white female nurses and male nurses from practicing in the United States Army Nurse Corps (ANC) prior to World War II. The Selective Service Act of 1940 strengthened the commitment of the War Department and Red Cross to recruit male nurses into the army. Yet despite this legislation and a desperate need for nurses during World War II, the army struggled to reconcile male nurses as being fit to be nurses in the military. Male nurses were relegated to other tasks such as fixing planes, or marching in the infantry.

\subsection{Nursing education}

Nursing education has been prone to stereotyping and discrimination related to male nursing students. Some male nursing students report a different set of expectations for them from the female nursing students such as the clinical

Published by Sciedu Press practice of infrequently allowing men into the Ob/Gyn clinical rotation. ${ }^{[1]}$ Male nursing students have reported feeling isolated due to the shortage of male nursing faculty and male role models within the profession. ${ }^{[10]}$

The attrition rate of male nursing students exceeds the attrition rate of the female nursing student by $28 \%$. Male nursing students are at particular risk for dropping out of nursing programs due to feelings of isolation, and role stressors. ${ }^{[11]}$ Additionally, male nursing students face barriers in nursing programs as a gender minority. O'Lynn's (2014) ${ }^{[12]}$ research identified the barriers that male nursing student's encounter as:

- Lack of male role models or instructors/mentors

- Lack of history of male nurses in the nursing curriculum

- Nurses are referred to as "she" in most nursing textbooks

- Differential treatment due to lack of males in nursing

These barriers are some of the reasons men are more likely to drop out or be unsuccessful in nursing education. The increase in momentum to increase gender diversity in nursing is halted by the current lack of men in nursing as mentors in education and practice.

\subsection{Lateral violence}

There was a dearth of studies found in the literature examining lateral violence experienced by an exclusively male nurse population. Typically studies have focused on lateral violence experiences of an exclusively female, or predominantly female sample, and if men were included in the studies, their experiences were not distinguished from those of their female counterparts. ${ }^{[13]}$ Studies exploring male nurses' experiences indicated that men in nursing experienced stereotyping, abuse, challenges, and isolation, but none of these studies identified these experiences as lateral violence. ${ }^{[14-17]}$

The prevalence of lateral violence in nursing practice has been demonstrated by multiple studies. Griffin $(2004)^{[13]}$ conducted an exploratory descriptive study at a large tertiary hospital in Boston, Massachusetts. There were 26 participants ( 24 female, 2 male). The results revealed that 25 $(96.1 \%)$ of the participants witnessed lateral violence and $12(46 \%)$ had experienced lateral violence directed at them. Szutenbach (2008) ${ }^{[18]}$ conducted a phenomenological study involving 9 female nurse participants in one small facility in the Midwest. The purpose of the study was to investigate bullying in nursing and its effects on job retention and satisfaction. Of the nine participants, eight had experienced bullying. Seven had reported leaving a job due to bullying. Emotional responses included feeling frustrated, powerless, 
fearful, broken, embittered, intimidated, pained, alone, distracted, and defeated. The majority of the participants felt the organization did not support them when they experienced bullying.

\subsection{Men in nursing}

Hart $(2005)^{[15]}$ conducted an online survey in the U.S. involving 498 male nurse participants to explore why more men were not nurses. The most frequent reason identified $(38 \%)$ was that nursing is traditionally considered a female profession. Other reasons identified included the stereotype that male nurses were gay (29\%), poor pay (15\%), and lack of role models (15\%). The most significant hurdle the male nurse participants faced in clinical practice was being viewed by female colleagues as "muscle" rather than being a competent nurse. Huebner (2017) ${ }^{[16]}$ conducted a qualitative study involving 10 male caregivers to examine the male caregiver's experience of providing intimate physical care. Findings revealed that male caregivers were perceived by patients, families, and sometimes female nurses as inappropriate or gay when providing the same intimate care as their female counterparts.

Harding (2007) ${ }^{[14]}$ conducted a qualitative study involving 18 male nurses in New Zealand using discourse analysis. The purpose of the study was to explore the construct of male nurses being gay. The findings indicated that the participants believed the majority of male nurses to be heterosexual yet the stereotype prevailed that male nurses were gay. The study was significant as it emphasized that therapeutic touch is essential to the provision of care but the stigmatization of male nurses who use touch as sexual predators creates barriers to care and acts as a deterrent to men entering the profession.

Rajacich, Kane, Willston, and Cameron (2013) ${ }^{[17]}$ conducted a qualitative study in Canada involving 16 male nurses to explore recruitment, retention, and job satisfaction. Sources of dissatisfaction included not feeling appreciated by the administration, not having enough full-time opportunities, being expected to provide physically demanding work and heavy lifting, fear of burnout, and stereotyping which excluded them from performing certain procedures because they were men. Participants felt isolated from female colleagues and believed that de-gendering nursing would attract more men to nursing.

\section{Methodology}

Two phenomenological studies independently explored the lived experiences of male nurses at both the educational and practice level. One study employed a descriptive phenomenological design to explore male nurses' lived experiences in nursing education and entry-level practice. ${ }^{[19]}$ The other study used a hermeneutic phenomenological design to explore male nurses' lived experiences with lateral violence in the workplace. ${ }^{[20]}$ Both qualitative studies but with a very different focus and unique populations of male nurses yet common findings. Table 1 compares the two studies.

Table 1. Comparison of the two studies

\begin{tabular}{|c|c|c|}
\hline Title & $\begin{array}{l}\text { Male Nurses Lived Experience with Nursing Education and } \\
\text { Entry into Practice }\end{array}$ & $\begin{array}{l}\text { Male Nurses’ Lived Experiences with Lateral Violence } \\
\text { in the Workplace }\end{array}$ \\
\hline Problem & $\begin{array}{l}\text { The general problem is the deficiency of gender diversity in } \\
\text { the nursing profession and the need for a nursing workforce } \\
\text { that mirrors the patient population (IOM, 2010). The precise } \\
\text { problem is the limited understanding of the male nurses } \\
\text { lived experience in entering the nursing profession. }\end{array}$ & $\begin{array}{l}\text { Lateral Violence (LV) is a significant problem for the } \\
\text { nursing profession with up to } 85 \% \text { of nurses having } \\
\text { experienced it }{ }^{[23]} \text {. } \\
\text { There is a dearth of studies exploring } L V \text { with an } \\
\text { exclusively male sample }\end{array}$ \\
\hline Purpose & $\begin{array}{l}\text { To explore male nurses’ lived experience with nursing } \\
\text { education and entry into practice. }\end{array}$ & $\begin{array}{l}\text { To explore male nurses' lived experiences with lateral } \\
\text { violence in the workplace. }\end{array}$ \\
\hline Method & Purposive snowball sampling & Purposive snowball, sampling \\
\hline Sample & $\begin{array}{l}\text { Participants }(\mathrm{N}=14) \text { male RN's in their first } 18 \text { months of } \\
\text { employment in health care organizations in the United } \\
\text { States. }\end{array}$ & $\begin{array}{l}\text { Participants (N-15) male RNs with a minimum of one } \\
\text { year of experience in practice. All participants were } \\
\text { Caucasian }\end{array}$ \\
\hline Design & Descriptive Phenomenology & Hermeneutic Phenomenology \\
\hline
\end{tabular}

\subsection{Male nurses lived experience with nursing education and entry into practice}

The descriptive phenomenological study collected data through SKYPE ${ }^{\mathrm{TM}}$ interviews with participants with less than 18 months of nursing experience with the expectation that participants would have good recall of their experience in their nursing education program as well as entry into practice. Three themes emerged from the interview data: discrimination, lack of support and negative effects. Table 2 identifies the themes with quotes to support them. 
The data revealed that 13 of the 14 participants had experienced discrimination during his nursing education experience or entry into employment. Of the 14 participants, 11 had experienced discrimination during both nursing education and entry into practice. The majority of the participants $(n=11)$ stated that they felt discriminated against at the earliest level, their entry into nursing education. Participants stated that they felt like "second class citizens", and were questioned "over and over" as to why they wanted to be a nurse. The participants suggested that it was more difficult for men to pass the nursing school interview process than the females. Participants sensed that the nursing faculty had a negative response to men desiring to enter nursing. The participants stated that being a man in a woman's world is very difficult. Participants felt that they were constantly judged differently than the female nurses.

Many of the participants $(n=6)$ stated when they went to the Dean of the nursing program, they felt rebuffed, ignored or appeased. Four of the participants stated that the management of the nursing program which included the Dean of Nursing and the liaison from the school affiliated hospital, listened to them, but did not address the issue in any way. The participants reported that the management at the hospital told them that if they had any issues regarding sexism to bring the issue to them, but when eight of the 14 participants approached management, participants felt patronized and appeased, with no results from the meetings noted. The participants suggested that management did not "have their backs" and did nothing to stop the discrimination at the nurs- ing education level or during entry into employment.

Many of the participants $(n=11)$ stated that the discrimination at the nursing program application level made them question why they wanted to become nurses even though they had previously thought the process through. Participants reported being upset and anxious, concerned about what other discriminatory practices they would encounter during their nursing education and eventual nursing employment. The participants indicated they felt angry at being questioned by female nurses over and over as to why they chose to enter a nursing program. The participants stated that the bias from the nursing faculty when working on a female unit such as labor and delivery made them very anxious and upset. As a result, participants questioned themselves regarding why they went into the nursing field.

The participants reported being angry when patients were asked by supervisors if it was okay for these men to be their nurses. The participants were also angry when they were expected to be the muscle on the unit for the female nurses, and still expected to carry out an equal assignment. The participants were upset when their schedules were changed so they did not view or assist with any laboring mothers in their labor and delivery rotation; they stated that they believe that they were denied many academic experiences because of these changes initiated by the faculty. The participants stated that the bias towards men in the academic setting and in the hospital setting, produced anxiety, sleepless nights, anger, and trepidation wondering what negative issue would occur in the future.

Table 2. Themes and support

\begin{tabular}{|c|c|}
\hline Theme & Support \\
\hline \multicolumn{2}{|l|}{ Discrimination } \\
\hline 1)Nursing Education Level $(\mathrm{N}=11)$ & $\begin{array}{l}\text { "The panel at the nursing school directly challenged me as to why a man would want to be a } \\
\text { nurse” }\end{array}$ \\
\hline 2)Entry into Practice $(\mathrm{N}=11)$ & $\begin{array}{l}\text { "My introduction to the hospital floor was a meeting with other nurses where I was told to } \\
\text { make sure I do the heavy lifting" }\end{array}$ \\
\hline \multicolumn{2}{|l|}{ Lack of Support } \\
\hline 1)Nursing Education Level ( $\mathrm{N}=8)$ & $\begin{array}{l}\text { "The supervisor obviously did not help me in any way at all: in fact she made it so much } \\
\text { harder for me as I now felt I had no way else to go" }\end{array}$ \\
\hline 2)Entry into Practice $(\mathrm{N}=6)$ & $\begin{array}{l}\text { "The management at the hospital could see that I was having a difficult time fitting in, but } \\
\text { they did not do anything to stop the other female nurses from harassing me" }\end{array}$ \\
\hline Negative Effects & "The application panel at the school made me so mad that I almost decided to give up the idea \\
\hline 1)Nursing Education Level $(\mathrm{N}=10)$ & $\begin{array}{l}\text { of nursing, but I knew that my experience as a medic was going to give me the "leg up" that } \\
\text { being a man would take away. Any man going into nursing school should know and } \\
\text { understand that they will be challenged" }\end{array}$ \\
\hline 2)Entry into Practice $(\mathrm{N}=11)$ & $\begin{array}{l}\text { "It took me about 6-7 months to feel accepted on the floor. I feel as if I had to work extra hard } \\
\text { to become part of the team, more so than the female nurses who joined the floor after me. } \\
\text { This just does not seem fair and surprised me as it is } 2017 \text {-you know-equal rights and all" }\end{array}$ \\
\hline
\end{tabular}


This study provided a detailed and comprehensive descrip- entry into practice. tion of the male nurses' lived experiences with nursing education and entry into practice. There are no other documented studies examining this phenomenon with exclusively male participants. Specifically this study revealed the unique discriminatory experiences of male nurses. This included being questioned by nursing education as to why they chose nursing; asked if they were "gay" or had some sort of "perversion". The male participants were banned from certain "sensitive" clinical areas such as Obstetrics and Gynecology by Clinical Instructors. The findings from this study illuminated how male nurses' experience with discrimination began at the nursing education level and continued into his

\subsection{Male nurses' experience with lateral violence}

This hermeneutic phenomenological study collected data from 15 participants by face to face interviews. Inclusion criteria for the study were: male RNs with at least one year of practice experience; having experienced lateral violence; and willingness to share those experiences. Four themes emerging from the data collected in this hermeneutic study: experiencing lateral violence in a variety of ways; lacking organizational support; reacting to lateral violence; and effects of lateral violence. Table 3 identifies the study themes and provides quotes from participant statements that support the themes.

Table 3. Themes and support

\begin{tabular}{|c|c|}
\hline Theme & Support \\
\hline \multirow{11}{*}{$\begin{array}{l}\text { Experiencing Lateral Violence in a Variety of Ways } \\
(\mathrm{N}=15)\end{array}$} & "I get a lot more overweight patients" \\
\hline & “I was discriminated against” \\
\hline & "Like the bullying in high school" \\
\hline & “Cutting my legs out from under me” \\
\hline & “Called me all kinds of names” \\
\hline & “Then she used profanity” \\
\hline & “Swear words and phrases” \\
\hline & "She would berate me" \\
\hline & “Angry and scream at me” \\
\hline & "She was going to blame it on me" \\
\hline & “I didn’t have any privacy” \\
\hline \multirow{4}{*}{ Lacking Organizational Support (N = 12) } & “Organization wouldn’t support me” \\
\hline & "Responded too slowly" \\
\hline & “Wasn’t adequately addressed” \\
\hline & "I can honestly say I had no support" \\
\hline \multirow{5}{*}{ Reacting to Lateral Violence ( $\mathrm{N}=15$ ) } & “A lot of anger” \\
\hline & “I had a severe anxiety attack” \\
\hline & “Made me very nervous” \\
\hline & “Depression, being angry” \\
\hline & "I always try to confront people” \\
\hline \multirow{7}{*}{ Effects of Lateral Violence ( $\mathrm{N}=15$ ) } & “A little burnt out” \\
\hline & “To become very depressed” \\
\hline & "I quit” \\
\hline & "Very stressful” \\
\hline & "Hard time leaving it at work" \\
\hline & "Frustrating and you feel powerless" \\
\hline & “Diminished my confidence” \\
\hline
\end{tabular}

Fifteen distinct lateral violence behaviors were identified as being experienced by the participants that are described in theme one. These behaviors were: exploitation of physical strength and heavy lifting assignments $(\mathrm{N}=5)$; discrimination based on male gender $(\mathrm{N}=6)$; harassment, intimidation, and stereotyping $(\mathrm{N}=1)$; sabotage $(\mathrm{N}=2)$; scapegoating ( $\mathrm{N}$
$=2)$; verbal affront $(\mathrm{N}=4)$; withholding information $(\mathrm{N}=1)$; backstabbing $(\mathrm{N}=1)$; non-verbal innuendo $(\mathrm{N}=1)$; failure to respect privacy $(\mathrm{N}=1)$; retaliation $(\mathrm{N}=1)$; humiliation $(\mathrm{N}=1)$; isolation for colleagues $(\mathrm{N}=1)$; spreading false rumors and defamation of character $(\mathrm{N}=1)$; and discourteous behavior and not being listened to $(\mathrm{N}=1)$. 
While some of the lateral violence behaviors experienced by the participants were comparable to those experienced by female nurses discussed in the literature some were unique to the male gender. For example five participants felt exploited for their physical strength, a type of occupational stereotyping. Six participants reported being discriminated against based on their male gender. These experiences took place in both the educational and practice settings. One participant was stereotyped by his colleague as being effeminate and repeatedly harassed. The experiences that were not unique to the male gender and shared with female nurses as documented in the literature, were sabotage, scapegoating, verbal affront, withholding information, backstabbing, non-verbal innuendo, failure to respect privacy, retaliation, humiliation, isolation from colleagues, defamation of character, and discourteous behavior.

Theme two addressed organizational support when participants experienced lateral violence. Twelve of the 15 study participants (80\%) expressed either no support, inadequate support, or support that came too late. Theme three addressed the participant's reactions to lateral violence. The study findings revealed that the participants reacted in a variety of ways to their lateral violence experiences. These reactions included: avoiding the perpetrator; confronting the perpetrator, reporting to management; doing nothing and learning to coping; and reacting emotionally; fighting back; discussing with colleagues; shutting down; remaining calm and talking things over; and staying focused on goals.

Theme four identified the effects lateral violence had on the participants. The effects of lateral violence included: eroded confidence; diminished self-esteem; leaving the profession; increased stress; disruption of home life; leaving a job; burnout; sleep disturbances; anxiety; adversely effecting patient care; depression; and anger.

This study provided a detailed and comprehensive description of the male nurses' lived experiences with lateral violence, specifically revealing the unique lateral violence experiences of male nurses' lack of organizational support, and gender discrimination.

\subsection{Comparison of findings}

While the two studies used different samples, were conducted independently, and had different purposes, their results shared several striking similarities. Table 4 compares the two studies. Similarities noted included: male gender discrimination in nursing education and practice; lack of organizational support when male nurses experienced discrimination; and adverse consequences of discrimination such as leaving a job, leaving the profession, anxiety, depression, diminished self-esteem.

Table 4. Comparison of study findings

\begin{tabular}{|c|c|c|}
\hline & $\begin{array}{l}\text { Male Nurses Lived Experience with Nursing } \\
\text { Education and Entry into Practice }\end{array}$ & $\begin{array}{l}\text { Male Nurses' Lived Experiences with Lateral } \\
\text { Violence in the Workplace }\end{array}$ \\
\hline Study Themes & $\begin{array}{l}\text { 1) Discrimination } \\
\text { 2) Lack of Support } \\
\text { 3) Negative Effects }\end{array}$ & $\begin{array}{l}\text { 1) Experiencing Lateral Violence in a Variety of Ways } \\
\text { 2) Lacking Organizational Support } \\
\text { 3) Reacting to Lateral Violence } \\
\text { 4) Effects of Lateral Violence }\end{array}$ \\
\hline Similar Findings & $\begin{array}{l}\text { 1) Gender discrimination of male nurses in nursing } \\
\text { education and entry into practice } \\
\text { 2) Lack of Support from management in nursing } \\
\text { education and nursing health care organizations } \\
\text { 3) Negative effects (anger, depression, diminished } \\
\text { self-esteem, desire to leave the nursing profession). }\end{array}$ & $\begin{array}{l}\text { 1) Gender Discrimination of Male Nurses in practice } \\
\text { and education } \\
\text { 2) Lack of organizational support ( } 80 \% \text { of participants) } \\
\text { 3) Adverse effects of LV (leaving job, leaving } \\
\text { profession, anxiety, depression, disturbed sleep, } \\
\text { disruption of home life, burnout, diminished } \\
\text { self-esteem, impaired patient care). }\end{array}$ \\
\hline
\end{tabular}

\section{Conclusions}

The two studies share several strikingly similar findings. Both studies revealed gender discrimination in education and practice; lack of organizational support when male nurses experienced gender discrimination; and negative effects of discrimination exemplified by such things as leaving a job, leaving the profession, anger, anxiety, depression, burnout, disturbed sleep, and diminished self-esteem. Findings from these studies suggest changes need to happen in both education and practice to recruit and retain men in the nursing profession.

Both of these studies gave male nurses a voice and an opportunity to share their stories. Insights gained by the robust experiences shared by the participants may be useful to the nursing profession to increase and retain male nurses in the profession. Nursing must recognize the value of the incorpo- 
ration of male and female characteristics of compassion in the nursing field. ${ }^{[21]}$ It is imperative to the nursing profession to raise the number of nurses in the United States as the nursing shortage grows daily and increasing the number of male nurses is a great place to start. ${ }^{[22]}$

Discrimination experienced by male nurses at both the educational and practice level is a significant problem that needs to be recognized and addressed by nurse educators, managers, and practitioners. These two studies provide compelling and corroborating evidence that discrimination of male nurses is a pervasive problem that adversely effects the recruitment and retention of this underrepresented group in the nursing workforce.

Male nurses still experience discrimination, social isolation, gender-based stereotypes, and lower job satisfaction rates than their female counterparts. There is still a paucity of male role models in the profession and recruitment strategies for men are insufficient. To attract more men into nursing it is imperative that the public stereotypes of men in nursing be changed. The caring aspect of male nurses should be emphasized, while not exploiting male nurses for their physical strength. Men should be recruited at a younger age, right out of high school, educators need to avoid referring to nurses as the stereotypical "she" and more male nurse role models should exist in both the academic and clinical settings. ${ }^{[17]}$

Discrimination against male nurses poses many dire consequences for the nursing profession. As the recruitment and retention of male nurses is one strategy to fill a critical nursing shortage, overt or subtle discrimination against men in nursing adversely impacts recruitment and retention, and therefore impairs efforts to address the nursing shortage. Preventing men from participating in certain areas of nursing practice and education experiences (e.g. labor and delivery) greatly restricts their capacity to function as nurses and denies the nursing profession of an untapped resource. Discrimination and lateral violence directed toward male nurses adversely effects their performance and this compromises patient care.

Male nurse discrimination is costly to organizations. In both studies many of the participants indicated there are thinking about leaving the nursing profession due to discrimination and lateral violence and others had already left jobs. Replacing a medical-surgical nurse can cost $\$ 92,000$, and replacing a specialty nurse, such as an emergency room nurse, can approximate $\$ 145,000 .^{[23]}$

The authors have made several recommendations based on the prevalence of gender discrimination toward male nurses at both the education and practice levels (see Table 5). These recommendations are based on the observations of the researchers and stories from the study participants. Strategies include: educating management regarding gender discrimination toward male nurses with concurrent organizational policies emphasizing "zero tolerance" and committees to enforce policies; gender diversity classes on cultural competency in nursing education curricula; workplace education on male nurse gender discrimination; building social networks for male student nurses, including male support systems; increasing studies related to men in the nursing profession to further understand the lived experiences of male nurses; include male nurse contributions in nursing textbooks, and lectures, and do not exclusively refer to nurses as "she" in nursing textbooks; discussing gender-based differences in expressions of care (e.g. physical touch) in nursing school and clinical practice; and addressing the stereotyping of male nurses as "muscle" in nurse education and practice.

Table 5. Recommended strategies to address the potential dire consequences

Management education to increase competencies in managing gender discrimination toward male nurses
Increasing senior management accountability to mitigate male nurse gender discrimination
Executive orders mandating "zero tolerance” to male gender discrimination
Internal organizational committees enforcing compliance to policies
Workplace education on male nurse gender discrimination
Increasing male nurse role models, teachers, and mentors in nursing education
Build social networks for male student nurses, including male support systems.
Increase studies related to males in the nursing profession to further understand the lived experiences of male nurses.
Add gender diversity to classes on cultural competency in nursing education curricula.
Include male nurse contributions in nursing textbooks, and lectures, and do not exclusively refer to nurses as "she” in nursing
textbooks
Discussing gender-based differences in expressions of care (e.g. physical touch) in nursing school and clinical practice
Addressing the stereotyping of male nurses as “muscle” in nurse education and practice


It is incumbent on nurse educators, managers, and practitioners to pay attention to the stories of male nurses in practice and education if the goal is to recruit and retain a diverse nursing workforce. As nursing looks to answer the problem of a current nursing shortage and the demands of the future all possible solutions need to be considered. Increasing men

\section{REFERENCES}

[1] Meadus RJ, Twomey J. Men Student Nurses: The Nursing Education Experience. Nursing Forum. 2011; 46(4): 269-279.

[2] Bureau's Industry and Occupation Statistics. Men in Nursing Occupations-Census. 2006. Available from: http://www. census .gov/people/io/publications/reports.html

[3] Bureau's Industry and Occupation Statistics. Men in Nursing Occupations-Census. 2013. Available from: http://www. census .gov/people/io/publications/reports.html

[4] Snavely TM. A brief economic analysis of the looming nursing shortage in the United States. Nursing Economics. 2016; 34(2): 98-100. Available from: http://search.proquest.com/docview/1783 691674 ? accountid $=35812$

[5] Krans B. The nursing shortage: Where are we going to find 1 million new nurses in the next five years? 2015. Available from: http://www.healthline.com/health-news/

[6] Eagly AH. Sex differences in social behavior: A social role interpretation. Hillsdale, NJ: Erlbaum. 1987.

[7] Clow KA, Riccardelli R, Bartfay WJ. Attitudes and stereotypes of male and female nurses: Influences of social roles and ambivalent sexism. Canadian Journal of Behavioral Sciences. 2014; 46(3): 446-455. https://doi.org/10.1037/a0034248

[8] Evans J. Men nurses: A historical and feminist perspective. Journal of Advanced Nursing. 2004; 47(3): 321-328. PMid:15238127 https://doi.org/10.1111/j.1365-2648.2004.03096.x

[9] Threat CJ. 'The hands that might save them': Gender, race, and politics of nursing in the United States during the Second World War. Gender and History. 2012; 24(2): 456-474. https ://doi .org/10 $.1111 / \mathrm{j} .1468-0424.2012 .01691 . \mathrm{x}$

[10] Sims G, Baldwin D. Race, class and gender considerations in nursing education. Nursing and Health Care: Perspectives on Community. 2011; 16(6): 16-21. Available from: http://www.ncbi.nlm.nih .gov/pubmed/8705647

[11] Pryjmachuk S, Easton K, Littlewood A. Nurse education: Factors associated with attrition. Journal of Advanced Nursing. 2008; 65(1): 149-160. PMid:19032508 https://doi.org/10.1111/j. $1365-2648.2008 .04852 . x$ in nursing is one viable solution. Mitigating discrimination toward male nurses will make nursing a more attractive profession for men and enhance their recruitment and retention.

\section{CONFliCtS OF INTEREST Disclosure}

The authors declare that there is no conflict of interest statement.
[12] O'Lynn C. Gender-based barriers for male nursing students in nursing education programs: prevalence and perceived importance. Journal of Nursing Education. 2014; 98(12): 18-25.

[13] Griffin M. Teaching cognitive rehearsal as a shield for lateral violence: An intervention for newly licensed nurses. Journal of Continuing Education in Nursing. 2004; 35(6): 257-263.

[14] Harding T. The construction of men who are nurses as gay. Journal of Advanced Nursing. 2007; 60(6): 636-644. https ://doi .org/ $10.1111 / j .1365-2648.2007 .04447 . x$

[15] Hart KA. What do men in nursing really think? Survey respondents speak out. Nursing. 2005; 35(11): 46-48. https : //doi .org/10.1 097/00152193-200511000-00045

[16] Huebner L. Male nurses and intimate care: Practicing gender in nursing. Conference Papers-American Sociological Association. 2017.

[17] Rajacich D, Kane D, Willston C, et al. If they do call-you nurse, it is always a 'male nurse': Experiences of men in the nursing profession. Nursing Forum. 2013; 48(1): 71-80. PMid:23379398 https://doi.org/10.1111/nuf.12008

[18] Szutenbach MD. Staff nurses' report of bullying between peers and its effects on job satisfaction and retention. (Order No. 3310902). Available from Proquest Dissertations \& Theses, Full Text (89219337). 2008. Available from: http://search.proquest.com/docvie w/89219337? accountid $=35812$

[19] Kronsberg S. Exploring Male Nurses' Experience in Nursing Education and Entry into Practice: A Phenomenological Study. 2017.

[20] Bouret J. Male nurses' lived experiences with lateral violence in the workplace (Order No. 10254089). 2017. Available from: https://search.proquest.com/docview/1870036783 ?accountid $=35812$

[21] Shaffer F. Men in nursing: Guided by the past, based in the present, and unfolding our future. American Journal of Nursing. 2014; 8(19): 26-31. Available from: http://www. thefreelibrary.com/Meninnursing3Agui dedbythepast, basedinthepresentanda0345622967

[22] Nursing Shortage and the Future of Nursing [Fact sheet]. 2015. Available from: http://www.bls.gov/news.release/ecopro.t08. htm

[23] Christie W, Jones S. Lateral violence in nursing and the theory of nurse as wounded healer. Online Journal of Issues in Nursing. 2014; 18(4): 1 . 